\title{
Radiology, Thorax, Chest
}

National Cancer Institute

\section{Source}

National Cancer Institute. Radiology, Thorax, Chest. NCI Thesaurus. Code C18990.

A specialty concerned with the use of $x$-ray and other forms of radiant energy in the diagnosis and treatment of disease of the thorax and chest. 